\title{
O texto de Rubem Braga através do olhar filológico: Levantamento de variantes em cinco crônicas do livro Um pé de milho
}

\author{
Rubem Braga's text through the philological view: finding variants in five chronicles of \\ the book Um pé de milho
}

Bárbara Bezerra de Santana Pereira* Universidade do Estado da Babia Jacobina, Bahia, Brasil

Manoel Mourivaldo Santiago Almeida** Universidade de São Paulo São Paulo, São Paulo, Brasil

\begin{abstract}
Resumo: O presente artigo tem por principal objetivo fazer o levantamento de variantes linguísticas/gráficas presentes em cinco crônicas de Rubem Braga. Essas crônicas foram inicialmente publicadas em jornais, entre os anos de 1943 a 1946, e posteriormente compiladas e publicadas no livro Um pé de milho, por sua vez, publicado no ano de 1948. Amparados nos postulados teórico-metodológicos da Crítica Textual, buscamos fazer uma inicial análise das cinco crônicas, cotejando três edições diferentes do livro Um pé de milho (1948, 1964 e 1989) e duas outras edições das mesmas crônicas presentes no livro 200 crônicas escolbidas (1977 e 2010).
\end{abstract}

Palavras-chave: Crítica Textual. Crônicas. Rubem Braga. Levantamento de variantes.

\begin{abstract}
This article has as its aim to find the linguistic/graphic variations present in five chronicles of Rubem Braga. Those chronicles were published firstly in newspapers, between the years 1943 and 1986, and later compiled and published in the book Um pé de milho, which was published in 1984. Supported by theoretical and methodological postulates of Textual Criticism, we seek to conduct an initial analysis of five chronicles, observing three different editions of the book Um pé de milho $(1948,1964$, and 1964) and two other editions of the same chronicles present in the book 200 crônicas escolbidas (1977 and 2010).

Keywords: Textual Criticism. Chronicles. Rubem Braga. Finding variants.
\end{abstract}

\section{INTRODUÇÃO}

Uma das propostas deste trabalho é refletir, mesmo que brevemente, acerca do método filológico, haja vista termos como corpus alguns testemunhos de crônicas do escritor Rubem Braga e pretendermos apontar variantes linguísticas/gráficas que ocorrem entre essas edições.

Mas afinal, do que trata a Filologia? Muitas são suas definições e essas variam de acordo com a época e com quem praticou o labor filológico. Como bem colocado por Spina (1994, p. 82): "Não tem sido fácil determinar com precisão o âmbito da Filologia,

* Estudante de doutorado (USP), professora da Universidade Estadual de Feira de Santana. Email: baletras02@hotmail.com.

* Doutor em Letras, professor da Universidade de São Paulo. E-mail: horas@terra.com.br. 
cujos objetivos têm variado conforme as épocas em que se praticou a atividade filológica, conforme os autores que a exerceram e até os lugares em que ela floresceu".

Desde as primeiras ocorrências do termo Filologia até nossos dias, esse vocábulo acumulou diversas acepções, sendo um dos argumentos levantados por teóricos para explicar sua gama de sentidos. Erich Auerbach (1972), ao definir Filologia, destaca o tempo de existência da ciência e a amplitude de seus objetos de estudo, explicando que

A Filologia é o conjunto das atividades que se ocupam metodicamente da linguagem do Homem [...]. Como se trata de uma ciência muito antiga e como é possível ocupar-se da linguagem de muitas e diferentes maneiras, o termo Filologia tem um significado muito amplo e abrange atividades assaz diversas. (AUERBACH, 1972, p.11, grifo nosso).

Sua famigerada polissemia nos leva a sentir a necessidade de uma discussão acerca de suas definições. Marquilhas (2010) aponta o termo como "incomodamente ambíguo", trazendo a divisão entre Filologia Oitocentista e Crítica Textual. Nessa mesma esteira de reflexão, temos Basseto (2005, p.37) afirmando que o conceito moderno de Filologia se fixa em duas vertentes: “[...] em sentido estrito, de filologia como a ciência do significado dos textos; e em sentido amplo, como a pesquisa científica do desenvolvimento e das características de um povo ou de uma cultura com base em sua língua ou em sua literatura." Essa última definição coaduna com a classificação que Marquilhas (2010) denomina de Filologia Oitocentista, na qual podemos colocar os estudos linguísticos de cunho histórico realizados por grandes nomes daquele século, além do enfoque no estudo cultural das sociedades, partindo da língua e da literatura. Já a primeira acepção tem como base principal, de início e fim, o estudo do texto, e denota o trabalho do editor textual, ou seja, o campo da Crítica Textual.

Chegamos à Crítica Textual, o sentido mais "clássico" e "autêntico" da Filologia. Como nos relata Auerbach (1979, p. 11), "Uma das formas mais antigas, a forma por assim dizer clássica e até hoje considerada por numerosos eruditos como a mais nobre e autêntica, é a edição crítica de textos." A história e as origens da Crítica Textual remontam aos bibliotecários de Alexandria, por volta do século III a. C., passando pelos estudos cristãos e profanos, da Idade Média à Renascença, até chegar à Idade Moderna, com a metodologia de Lachmann, e aos dias de hoje. Apesar de todo esse tempo e contextos diversos e divergentes, a Crítica Textual resiste com seu principal objetivo: a constituição do texto genuíno, fidedigno. Atualmente, ganha outros contornos, mas mantém seu esteio teórico. Como nos lembra Blecua (1983, p. 19): “A crítica textual nasce com o livro a fim de que as obras mantenham um grau máximo de pureza e inteligibilidade. É uma ancilla libri que intenta conservá-lo sempre em seu aspecto mais puro."”

Em se tratando do texto literário, de sua tradição e transmissão, temos na Crítica Textual a disciplina que nos conduz ao que possivelmente seja o texto fidedigno. Como

1 Tradução nossa. "La crítica textual nasce con el libro a fin de que las obras mantengan un grado máximo de pureza e inteligibilidade. Es una ancilla libri que intenta conservalo siempre en su aspecto más puro." (BLECUA, 1983, p. 19) 
bem colocado por Castro (1990, p.1), "Enquanto os escritores escrevem [...] o crítico textual vê assegurado o seu pleno emprego, quer como arqueólogo dos documentos gráficos, quer como terapeuta dos textos".

Entretanto, salientamos que o presente trabalho não almeja realizar uma edição crítica, busca sim apresentar um simples exercício de cotejo entre versões de um mesmo texto, analisando e classificando suas variantes. Exercício este que faz parte do labor filológico, mas que, por agora, não culminará na apresentação de uma edição crítica.

\section{RUBEM BRAGA: O CRONISTA-POETA}

Para contextualizarmos o corpus do presente trabalho, apresentaremos brevemente aspectos referentes à vida e obra do cronista Rubem Braga. Nascido a 12 de janeiro de 1913, na cidade de Cachoeiro de Itapemirim, estado do Espírito Santo, Rubem Braga é considerado um de nossos maiores escritores. Sua importância na literatura brasileira o figura como principal nome da crônica, fazendo com que esse gênero, considerado "menor", ganhasse contornos inovadores e marcadamente líricos. A partir da observação e análise da realidade cotidiana, Rubem Braga relata e descreve acontecimentos de forma realista e poética. De acordo com José Castello (1996, p. 10), a crônica para Braga foi "[...] um gênero eminentemente confessional, e os fatos, nada mais que os fatos, sua matéria-prima", ao mesmo tempo alicerçada pela "força do lirismo e de vasta imaginação".

Como seria o processo de escrita de Braga? Ao lermos a biografia do cronista, escrita por Castelo (1996), vemos uma descrição da difícil e trabalhosa tarefa de escrever. O biógrafo chega a afirmar que essa era uma "atividade torturante" para Braga e nos descreve a seguinte cena:

O Urso se levanta, ronda pela sala, ajeita uma moldura fora de linha, dá voltas, remexe nas plantas, assobia. Por fim, volta à rede e ao caderno para anotar meia dúzia de linhas. Agora podemos aproveitar que ele se levantou para nova volta pelo jardim e dar uma espiada em seus originais. A escrita é suja, remendada, bordada por garranchos e riscos grosseiros. Há palavras dependuradas nas margens, palavras empilhadas sobre palavras, anotações transversas, comentários rasantes para si mesmo, do tipo: "Está péssimo", "Reescrever correndo", "Cortar". O cronista é impiedoso consigo mesmo, e é dessa rigidez e impaciência que nasce o texto elegante e fluente que tanto gostamos de ler. (CASTELO,1996, p. 70)

Essa descrição de seu fazer literário instiga, principalmente, o crítico genético, que, através dessa "escrita suja, remendada, bordada por garranchos e riscos grosseiros", encontraria um rico caminho para refletir acerca do escrever rubembraguiano.

Quanto ao estilo, à recepção da obra e à transcendência da mera informação, Chagas e Rio Doce (2013) observam que a crônica rubembraguiana "Serve o leitor de uma narrativa em primeira pessoa, que lembra a tradição oral do contador de histórias, amplifica a mensagem que deseja passar, desloca-a do campo informativo e, assim, dá 
margem a diversas interpretações." E Afrânio Coutinho (1971, p. 120) assim resume a técnica e o talento do cronista-poeta capixaba:

De todas as figuras de cronistas contemporâneos aquela que mais atrai a admiração é Rubem Braga, o escritor que entra para a história literária exclusivamente como cronista. Sua técnica é dar pouco apreço aos fatos do mundo real e muita vez os escolhe como simples pretexto para divagação pessoal. É seguramente o mais subjetivo dos cronistas brasileiros. E o mais lírico. Muitas de suas crônicas são poemas em prosa. Apresentando a originalidade de uma imaginação poética e erradia, Rubem Braga, em seu lirismo escreve sem ornatos e alcança às vezes a simplicidade clássica numa língua despojada, melodiosa, direta.

Sua escrita é sua vida, tarefa árdua, mas essencial. Segundo Castelo (1996), Braga "escreve até o dia de sua morte". Poucas horas antes de morrer, ele envia seu último texto para a redação da Revista Nacional. Falece aos 20 dias do mês de dezembro do ano de 1990, na cidade do Rio de Janeiro.

\section{APRESENTANDO O CORPUS}

Ao logo de 62 anos de atividade jornalística, Braga escreveu cerca de 15 mil crônicas, publicadas em diversos jornais e revistas, também compiladas e publicadas em vários livros, dentre eles, o Um pé de milho, publicado pela primeira vez em 1948, pela José Olympio Editora. Até os dias de hoje, suas crônicas são fonte e corpus para novas publicações, sejam em forma de novas seleções ou reedições de obras consagradas.

Tendo em vista o trabalho aqui apresentado, foram escolhidas cinco crônicas do livro Um pé de milho e que também se encontram presentes no livro 200 crônicas escolbidas. São elas: Foi uma Senhora (1943) ${ }^{2}$, Aula de Inglês (1945), Passeio à Infância (1945), A Companbia dos Amigos (1945) e História do Caminhão (1946).

Para nosso exercício de cotejo e levantamento de variantes, escolhemos, do livro Um pé de milho, a primeira edição (que chamaremos de Testemunho A), datada de 1948 e publicada pela Editora Livraria José Olympio; a segunda edição (Testemunho B), de 1964, publicada pela Editora do Autor; e a quarta edição (Testemunho C), de 1982, publicada pela Editora Record. Destacamos a quarta edição por ter sido a última publicada com o autor em vida, haja vista a quinta ter saído só no ano de 1993, três anos depois de sua morte. Caso fosse o intuito de realizar uma edição crítica dessas crônicas, fatalmente usaríamos a quarta edição como texto de base.

Além das edições acima, escolhemos também cotejar essas mesmas crônicas encontradas em duas outras edições do livro 200 crônicas escolhidas. São elas as de 1977 (Testemunho D) e de 2001 (Testemunho E), todas duas pela Editora Record.

Das trinta e quatro crônicas presentes no livro Um pé de milho, 23 estão no livro 200 crônicas escolbidas. Sobre as crônicas escolhidas, o próprio Rubem Braga, na edição de 1977 , coloca uma nota informando como se deu esse processo de escolha dos textos, vejamos:

${ }^{2}$ Esses anos correspondem ao período em que as crônicas foram publicadas em jornais. 
Tirante as duas últimas, as crônicas deste volume são escolhidas entre as de meus livros. A primeira escolha foi feita por Fernando Sabino, mas eu troquei uma ou outra, levado por algum motivo, às vezes sentimental. (BRAGA, 1977) ${ }^{3}$

Como já colocado, com o intuito de observar e analisar o processo de transmissão dessas crônicas, escolhemos cinco edições e fizemos o cotejo entre elas. A seguir, apresentamos um levantamento das variantes encontradas entre as edições escolhidas e, a partir desse levantamento, poderemos, mesmo que superficialmente, refletir acerca das naturezas e motivo dessas variantes.

\section{LEVANTAMENTO E ANÁLISE DAS VARIANTES}

Esta seção do artigo apresenta as variantes, que consideramos substantivas, encontradas entre as crônicas escolhidas como corpus de trabalho. Tomamos de empréstimo as terminologias utilizadas por Blecua ${ }^{4}$ (1983) para classificarmos essas variantes. Sendo assim, as apresentamos como referentes à Alteração da Ordem, Omissão, Adição e Substituição.

O levantamento apresenta trechos das crônicas escolhidas, com as variantes destacadas (em negrito e sublinhado) e letras em caixa-alta identificando os cinco testemunhos utilizados no cotejo:

Testemunho A - Edição de 1948, de Um pé de milho;

Testemunho B - Edição de 1964, de Um pé de milho;

Testemunho C - Edição de 1982, de Um pé de milho;

Testemunho D - Edição de 1977, de 200 crônicas escolbidas;

Testemunho E - Edição de 2001, de 200 crônicas escolhidas.

No início de seu livro, intitulado Manual de crítica textual, Alberto Blecua observa que a Crítica Textual “[...] é a arte que tem como fim apresentar um texto depurado no possível de todos aqueles elementos estranhos ao autor." Como já colocado, o presente trabalho não objetiva apresentar uma análise aprofundada da transmissão dessas crônicas. Sendo assim, não temos como afirmar que as variantes aqui apresentadas sejam, de fato e completamente, autorais. Independentemente dessa constatação, ressaltamos que as modificações encontradas possuem substancialidade, haja vista os exemplos a seguir.

\footnotetext{
${ }^{3}$ Nota introdutória, sem número de página.

${ }^{4}$ Blecua (1983) utiliza essas terminologias (a saber: adição, omissão, substituição e alteração da ordem) para classificar o que denomina "erro". Aqui estas classificações serão utilizadas para analisar o que chamamos de "variante".

5 Tradução nossa. "[...] es el arte que tiene como fin presentar un texto depurado en lo posible de todos aquellos elementos extraños al autor.” (BLECUA, 1983, p.8-9)
} 


\subsection{ALTERAÇÃO DA ORDEM}

\subsubsection{Alteração da ordem pronominal}

A/B/C: Mas basta! Por que maldita inclinação hei de eu estar sempre a explicar meu temperamento?

D/E Mas basta! Por que maldita inclinação hei eu de estar sempre a explicar meu temperamento?

(Foi uma senhora, 1943)

A: Abençoada eternamente seja aquela mulher. Eu conheci-a dez minutos depois de minha morte.

B/C/D/E: Abençoada eternamente seja aquela mulher. Eu a conheci dez minutos depois de minha morte.

(Foi uma senhora, 1943)

\subsection{OMISSÃO}

\subsubsection{Pontuação}

A: "Eu não sentia mais nenhuma dor aguda, mas ainda estava completamente embrulhado naquele sentimento da morte, a morte anunciada, ou, pior ainda, insinuada,

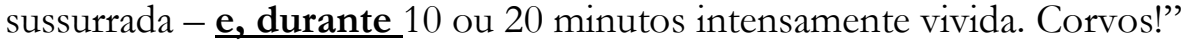

B/C/D/E: "Eu não sentia mais nenhuma dor aguda, mas ainda estava completamente embrulhado naquele sentimento da morte, a morte anunciada, ou pior ainda, insinuada, sussurrada - e durante 10 ou 20 minutos intensamente vivida. Corvos!"

(Foi uma senhora, 1943)

\subsubsection{Lexical}

A/B/C: "Eu era o beque do Copacabana e atrás de mim estava o guardião e pintor Di Cavalcanti."

D/E: "Eu era o beque do Copacabana e atrás de mim $\underline{\boldsymbol{\emptyset}}$ o guardião e pintor Di Cavalcanti."

(A companbia dos amigos, 1945)

\subsection{ADIÇÃO}

\subsubsection{Pontuação}

A: "Ela soltou um pequeno suspiro satisfeita: a demora da minha resposta a havia deixado apreensiva."

B/C/D/E: "Ela soltou um pequeno suspiro, satisfeita: a demora da minha resposta a havia deixado apreensiva." 
A/B/C: "Sim, de todos os tipos humanos e divinos nenhum como aquela senhora me impressionou tanto; e quando a vi novamente, meses depois, em um bar... Mas para que falar nessas coisas?"

D/ E "Sim, de todos os tipos humanos e divinos, nenhum como aquela senhora me impressionou tanto; e quando a vi novamente, meses depois, em um bar... Mas para que falar nessas coisas?"

A: "Dezembro de 43"

(Foi uma senhora, 1943)

B/C/D/E: "Dezembro, 1943"

\subsubsection{Adição de uma locução}

A: "Tratei de apanhar a escova de dentes, a pequena, frívola e patética escova q que anda sempre na bolsa das senhoras deshonestas e no bolso dos políticos perseguidos."

$\mathrm{A} / \mathrm{B} / \mathrm{C} / \mathrm{D} / \mathrm{E} / \mathrm{F}$ : "Tratei de apanhar a escova de dentes, a pequena, a frívola e patética escova de dentes que anda sempre na bolsa das senhoras desonestas e no bolso dos políticos perseguidos."

(História de caminhão, 1946)

\subsection{SUBSTITUIÇÃO}

\subsubsection{Uso do gênero}

A: "Primeiro vamos lá embaixo no córrego; pegaremos duas pequenas carás douradas."

B/C/D/E: "Primeiro vamos lá embaixo no córrego; pegaremos dois pequenos carás dourados."

(Passeio à infância, 1945)

A/B/C: "É um passarinho miúdo: imagine uma saíra grande que de súbito aparecesse a um menino que só tivesse visto coleiras e curiós, ou pobres cambaxirras."

D/E: "É um passarinho miúdo: imagine uma saíra grande que de súbito aparecesse a um menino que só tivesse visto coleiros e curiós, ou pobres cambaxirras."

(Passeio à infância, 1945)

\subsubsection{Uso de letras maiúsculas e minúsculas}

A: "Com dois paus de pita, faremos uma balsa, e, como o Carnaval é no mês que vem, vamos apanhar tabatinga para fazer formas de máscaras."

B/C/D/E: "Com dois paus de pita, faremos uma balsa, e, como o carnaval é no mês que vem, vamos apanhar tabatinga para fazer formas de máscaras."

(Passeio à infância, 1945) 
A: "Joel Silveira mora em Botafogo, mas como sua casa é perto do tunel velho jogará no Copacabana."

B/C/D/E: "Joel Silveira mora em Botafogo, mas como sua casa é perto do Túnel Velho jogará no Copacabana."

(A companbia dos amigos, 1945)

A: "A mulher, chegando em casa, opinou que o melhor era eu ir á Policia; mas não creio que fique bem a um homem honrado ir á Policia por causa de negocios de dinheiro."

B/C/D/E: "A mulher, chegando em casa, opinou que o melhor era eu ir à polícia; mas não creio que fique bem a um homem honrado ir à polícia por causa de negócios de dinheiro."

(História de caminhão, 1946)

\subsubsection{Uso de palavras estrangeiras}

A: "Eu era o back do Copacabana e atrás de mim estava o guardião e pintor Di Cavalcanti."

B/C/D/E: "Eu era o beque do Copacabana e atrás de mim estava o guardião e pintor Di Cavalcanti."

(A companbia dos amigos, 1945)

A: Copacabana venceu o primeiro por 1 x 0 (houve um goal deles anulado porque Di Cavalcanti declarou que passara por cima da trave; e, como não havia trave, ninguém pôde desmentir).

B/C/D/E: Copacabana venceu o primeiro por 1 x 0 (houve um gol deles anulado porque Di Cavalcanti declarou que passara por cima da trave; e, como não havia trave, ninguém pôde desmentir).

(A companbia dos amigos, 1945)

A: "Doce é a companhia dos amigos; doce é a visão das mulheres em seus maillots, doce é a sombra das barracas; e ali ficamos debaixo do sol, junto do mar, perante as montanhas azuis."

B/C/D/E: "Doce é a companhia dos amigos; doce é a visão das mulheres em seus maiôs, doce é a sombra das barracas; e ali ficamos debaixo do sol, junto do mar, perante as montanhas azuis."

(A companbia dos amigos, 1945)

\subsubsection{Provavelmente por correção}

A: "[...] pois digam o que disserem sobre a inflação, em minha casa sempre reinou uma grande desinflação."

$\mathrm{B} / \mathrm{C} / \mathrm{D} / \mathrm{E}$ " [...] pois digam o que disserem sobre a inflação, em minha casa sempre reinou uma grande deflação."

(História de caminhão, 1946) 


\section{CONSIDERAÇÕES FINAIS}

Para finalizarmos, gostaríamos de ratificar que este artigo traz um despretensioso exercício de levantamento e breve análise de variantes. Das 23 encontradas, duas foram por alteração da ordem, correspondendo a $9 \%$; quatro por omissão, correspondendo a $17 \%$; quatro por adição, correspondendo a 17\%; e treze por substituição, correspondendo a $57 \%$. Sendo assim, com mais da metade das ocorrências, a substituição é o fenômeno de variante que mais se fez presente nesta análise. Observemos o gráfico que se segue:

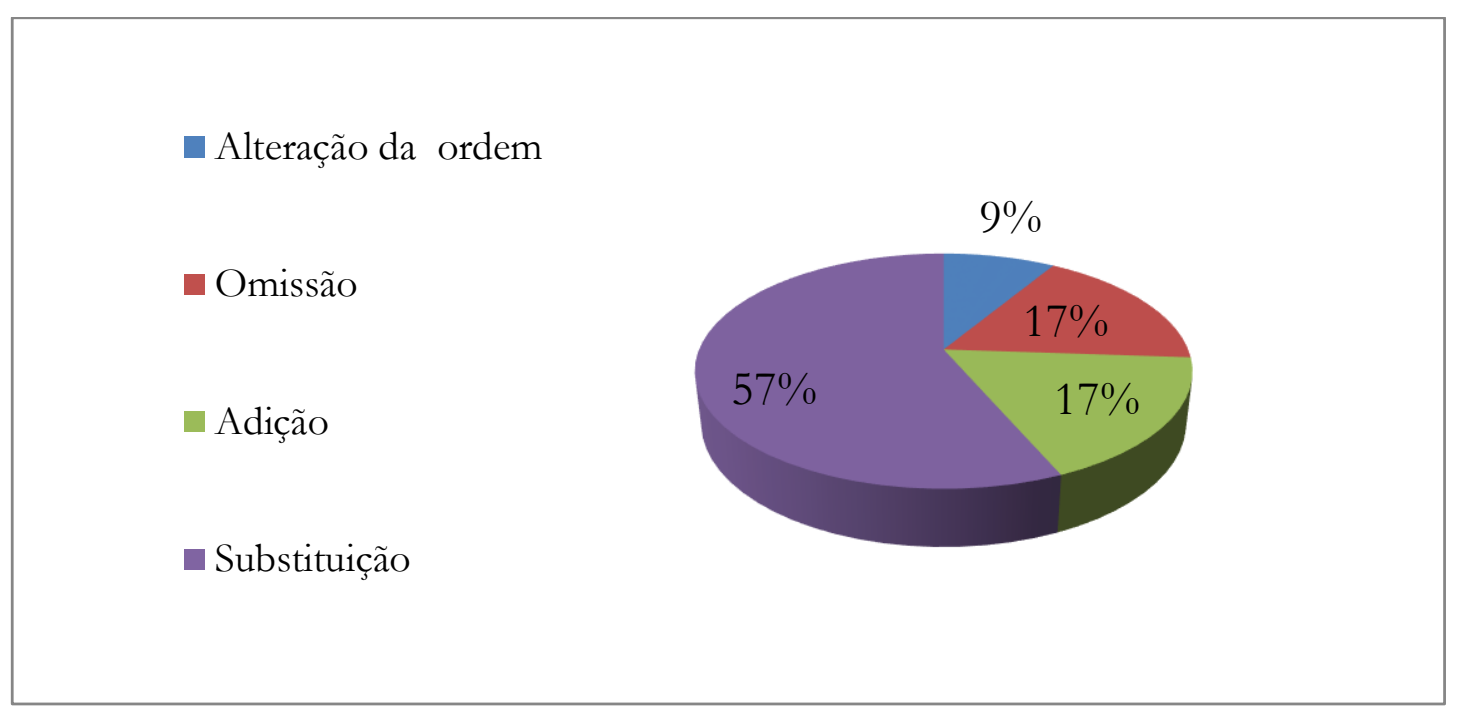

Gráfico 01: Variantes

Através de alguns princípios da Crítica Textual aqui abordados, pudemos apresentar a obra rubembraguiana por um prisma diferente. Sabemos que este foi apenas um leve exercício filológico, mas sentimos que uma obra tão vasta e rica muito tem a nos oferecer. Pois, definitivamente, o texto escrito de qualquer espécie é um manancial infindável de descobertas.

\section{REFERÊNCIAS}

AUERBACH, Erick. Introdução aos estudos literários. Tradução de José Paulo Paes. São Paulo: Cultrix, 1972.

BASSETO, Bruno Fregni. Elementos de filologia românica: história externa das línguas. 2. ed. São Paulo: EDUSP, 2005.

BLECUA, Alberto. Manual de crítica textual. Madrid: Editorial Castalia, 1983.

BRAGA, Rubem. Um pé de milho. Rio de Janeiro: José Olympio, 1948. 
- Um pé de milho. 2. ed. Rio de Janeiro: Editora do Autor, 1964.

. Um pé de milho. 4. ed. Rio de Janeiro: Record, 1982.

200 crônicas escolbidas. Rio de Janeiro: Record, 1977.

. 200 crônicas escolbidas. 33. ed. Rio de Janeiro: Record, 2010.

CASTELLO, José. Na cobertura de Rubem Braga. Rio de Janeiro: José Olympio, 1996.

CASTRO, Ivo. Enquanto os escritores escreverem... In: IX Congresso Internacional da Associação de Linguística e Filologia da América Latina. Campinas, 1990.

CHAGAS, Adriano; RIO DOCE, Cláudia Camardella. Imagens suprarreais para Um pé de milho, de Rubem Braga. Revista Estação Literária. Londrina, v. 11, p. 285-296, jul. 2013. COUTINHO, Afrânio. A literatura no Brasil. v. 6. 2. ed. Rio de janeiro: Editorial Sul Americana S. A., 1971.

MARQUILHAS, Rita. Filologia oitocentista e crítica textual. In: ALVES, Fernanda Mota et al. (Org.), Filologia, Memória e Esquecimento. Act. 20. Lisboa, Húmus, pp. 355- 367, 2010.] Universidade de Lisboa, Centro de Linguística. Disponível em: http://clul.ul.pt/files/rita marquilhas/MarquilhasMemoriaEsquecimento.pdf. Acesso em: jun. 2017.

SPINA, Segismundo. Introdução à edótica: crítica textual. 2. ed. São Paulo: Ars Poética, Editora da Universidade de São Paulo, 1994.

Recebido em: 17/05/2017

Aprovado em: 25/08/2017

Publicado em: 01/12/2017 